\title{
La dimensión sinodal y colegial del ministerio apostólico
}

The Synodal and Collegial Dimension of Apostolic Ministry

JAUME FONTBONA I MisSÉ

Facultad de Teología de Catalunya

ORCID: 0000-0002-6855-9922 | jaumefm@gmail.com

Fecha de recepción: 7/10 2021

Fecha de aceptación: 6/12/2021

https://doi.org/10.52039/seminarios.v66vi229.772

RESUMEN: Este artículo reflexiona sobre la dimensión colegial y sinodal del obispo y del presbítero. Destaca que el primer collegium es el presbyterium y que el colegio episcopal, como gran aportación del Concilio Vaticano II, surge a partir de la eclesiología de Cipriano de Cartago, aunque la colegialidad no se comprende de la misma manera. Y nota que, en la eucaristía dominical, los asistentes hacen una experiencia sinodal.

PALABRAS CLAVE: collegium, comunidad sacerdotal, presbyterium, sensus fidei, sinodalidad.

ABSTRACT: This article reflects on the collegial and synodal dimension of the bishop and the priest. It emphasized that the first collegium is the presbyterium and that the episcopal college, as a great contribution of the Second Vatican Council, arises from the ecclesiology of Cyprian of Carthage, although collegiality is not understood in the same way. Finally note that, in the Sunday Eucharist, the assistants have a synodal experience.

KeYwORDS: Collegium, Priestly Community, Presbyterium Sensus fidei, Synodality.

\section{INTRODUCCIÓN}

En el seno del único ministerio apostólico, el Espíritu suscita la diversidad: obispo, presbíteros y diáconos. Diversidad determinada por el don recibido en la ordenación y por su origen apostólico. Así, el diaconado, por su origen apostólico (la plegaria de ordenación diaconal recuerda a los Siete en referencia a su institución narrada a Hch 6,1-7), es un orden no colegial respecto al episcopado y al presbiterado, ambos colegiales.

Precisamente el rito de ordenación expresa, con la imposición de las manos, este carácter colegial o no, cuando todos los miembros del mismo 
colegio imponen las manos al nuevo candidato. Lo cual no acontece en el caso del diaconado, pues únicamente el obispo impone las manos al ordenado de diácono.

La entrada en el propio orden se visibiliza con el beso de paz que se dan entre sí quienes pertenecen al mismo orden, a saber, obispo con obispos, presbítero con presbíteros, diácono con diáconos; además, el recién ordenado recibe el beso de paz del propio obispo o del obispo que preside la ordenación. Lo mismo acontece en el sacramento de la confirmación, donde el beso de paz con el obispo (que a menudo pasa desapercibido) expresa que el recién confirmado entra a formar parte del ordo de los cristianos, de la comunidad sacerdotal.

La Iglesia ha recibido del Señor resucitado el ministerio apostólico o de comunión y los apóstoles lo han transmitido a sus colaboradores y sucesores, o bien en su plenitud, a los obispos, o bien bajo particulares aspectos, a los presbíteros y diáconos $(L G 20 ; 28)$. Gracias al diálogo ecuménico entre las Iglesias y comunidades eclesiales, surge la posibilidad de definir la identidad del ministerio de comunión desde los rasgos que la constituyen, a saber, personal, colegial y sinodal.

El objeto de este estudio es esbozar los rasgos colegial y sinodal del ministerio apostólico, teniendo en cuenta que la Iglesia católica latina siempre ha subrayado el carácter personal del ministerio, o sea, el don recibido por la imposición de manos y la plegaria de ordenación, elementos que, durante la Escolástica dejan de ser esenciales y constitutivos, y que recupera Pío XII. ${ }^{1}$

El Concilio Vaticano II, al reconocer la sacramentalidad del episcopado ( $L G 21$ ), subraya el carácter colegial del mismo ( $L G 22-23 ; C D 4)$. Por su parte, la colegialidad del presbiterado, aunque no sea explicitada, se sobreentiende al formar un solo presbiterio con su obispo ( $L G 28 ; P O$ 7-8). Hay que esperar al diálogo ecuménico para hablar del carácter sinodal del ministerio apostólico, y al obispo de Roma Francisco para establecer la sinodalidad como elemento constitutivo de la Iglesia. En efecto, en su discurso con ocasión de la conmemoración del 50 aniversario de la institución del Sínodo de los obispos, el obispo de Roma Francisco dijo que "el camino de la sinodalidad es el camino que Dios espera de la Iglesia del tercer milenio". Y también dijo que la sinodalidad es una "dimensión constitutiva de la Igle-

1. El 30 de noviembre de 1947 Pío XII publica la Constitución apostólica sobre el sacramento del orden (Sacramentum ordinis), que declara como materia del sacramento del orden de los presbíteros la imposición de les manos, y no la entrega de los instrumentos (como lo era desde la Escolástica). La doctrina anterior viene determinada por el Decreto del Concilio de Florencia, aprobado en la sesión VIII (22-XI-1439), Bulla unionis Armenorum. 
sia"; ${ }^{2}$ precisamente el Documento de Chieti (2017), de la Comisión Internacional mixta para el diálogo teológico entre la Iglesia católica y la Iglesia ortodoxa, ve la sinodalidad como una cualidad fundamental de la Iglesia. ${ }^{3}$

Hay que recordar que todas las personas bautizadas caminamos juntas con dones y carismas diferentes, ${ }^{4}$ lo cual define el carácter sinodal de cada Iglesia local y de la entera Iglesia de Dios, pues esta existe como comunión. En el seno de la comunidad sacerdotal surge el ministerio de comunión como don del Espíritu a la Iglesia de Cristo. Y el Espíritu concede este don al servicio de la comunión y de la unidad en la fe del cuerpo de Cristo: la Iglesia. El Espíritu es el hilo que posibilita el tejido de la comunión eclesial con la trama del ministerio apostólico y la urdimbre de los variados carismas suscitados en el seno de la comunidad sacerdotal. ${ }^{5}$ Luego las estructuras sinodales visibilizan su acción en la Iglesia y por ella en el mundo e impiden apagarlo $(1 \mathrm{Te} 5,19)$ y entristecerle (Ef 4,30).

Además, el rasgo sinodal del ministerio apostólico, como recuerda el Documento de Ravenna,${ }^{6}$ debe estar presente en los tres ámbitos de la comunión eclesial: local, interlocal o regional y universal o ecuménico. Por eso existen las estructuras sinodales en la Iglesia local (ámbito local); en la agrupación de Iglesias locales en una región, nación, continente (ámbito regional o interlocal); y en el seno de la comunión de las Iglesias (ámbito ecuménico o universal). ${ }^{7}$

\section{LA COLEGIALIDAD}

La colegialidad de un orden expresa el vínculo sacramental entre quienes forman parte del mismo. Este vínculo se visibiliza en la liturgia de orde-

2. Francisco, Discurso en la conmemoración del 50 aniversario del Sínodo de los obispos (17/10/2015); C. M. Galli, «Líneas teológicas, pastorales y espirituales del magisterio del Papa Francisco», Medellín 43 (2017) 131.

3. Commission internationale mixte pour le dialogue théologique entre l'Église catholique romaine et l'Église orthodoxe, Synodalité et primauté au premier millénaire : vers une compréhension commune au service de l'unité de l'Église, n. 3 : «La synodalité est une qualité fondamentale de l'Église dans son ensemble».

4. El obispo de Roma Francisco destaca que los carismas están al servicio de la comunión evangelizadora (Evangelii gaudium 130-131).

5. Francisco, Evangelii gaudium 130. Donde dice que los carismas suscitados por el Espíritu Santo son dones para renovar y edificar a la Iglesia.

6. Documento de Ravenna I,10; DdE 43 (2008) 922, 435. Intuición ya formulada en una publicación precedente: J. Fontbona i Missé, Comunión y sinodalidad. La eclesiología eucarística después de N. Afanasiev en I. Zizioulas y J.M.R. Tillard, Barcelona1994.

7. J. Fontbona, «Les estructures sinodals de l'Església local», Revista Catalana de Teologia 43 (2018) 349-381. 
nación por la imposición de las manos de todos los miembros del mismo colegio. Así pues, existe el colegio episcopal, o sea, un único episcopado en el seno de la Iglesia de Dios extendida por todo el mundo, y el colegio presbiteral, o sea, un único presbiterio en cada Iglesia local.

Hay que tener en cuenta que la primera manifestación de colegialidad la encontramos en el seno de una Iglesia local, o sea, el obispo local rodeado de los presbíteros de su Iglesia. La primera información la hallamos en Ignacio de Antioquia: «Seguid todos al obispo, como Jesucristo al Padre, y al presbiterio ( $\tau \tilde{\varphi}$ $\pi \rho \varepsilon \sigma \beta \nu \tau \varepsilon \rho i ́ \omega)$ como a los apóstoles» ${ }^{8}$ (IgEsm $8,1)$. Vemos que se relaciona al obispo con Jesucristo y al presbiterio con los apóstoles. Y esta relación tipológica -a imagen del trono celestial o de la liturgia celestial- entre el presbiterio y los apóstoles la encontramos en otros lugares de las cartas consideradas auténticas. ${ }^{9}$ En concreto: «El obis-

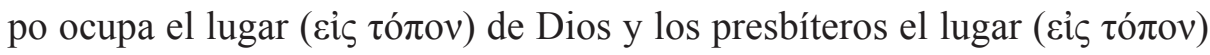

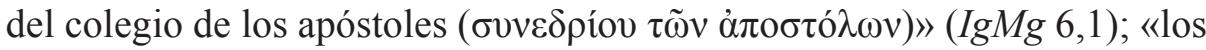

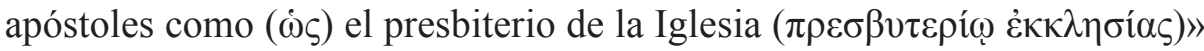
$($ IgFld 5,1$) ;$ «[...] Más aún someteos al presbiterio como a los apóstoles de

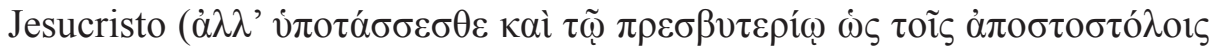

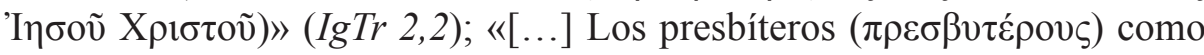

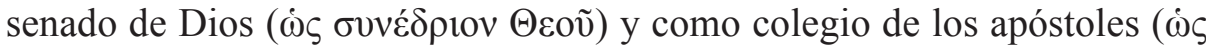

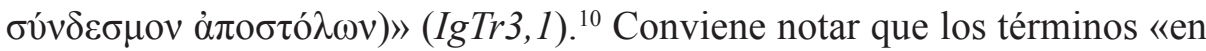

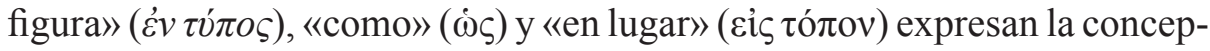
ción tipológica, ${ }^{11}$ o sea, una identidad en la diversidad entre los conceptos o personajes relacionados. En este caso, el presbiterio representaría al colegio apostólico (identidad en la diferencia), y el obispo a Jesucristo. En consecuencia, la última cena de Jesús con los apóstoles se actualiza en la eucaristía de la Iglesia local, donde el obispo ocupa el lugar de Cristo y los presbíteros el lugar de los apóstoles.

8. D. Ruiz Bueno (ed.), Padres apostólicos, Madrid 1967, traduce por colegio de ancianos (p. 493).

9. A. Miltos, Collégialité et synodalité. Vers une compréhension commune entre catholiques et orthodoxes, Paris 2019, 296-300.

10. Se sigue la edición crítica de J. Rius-Camps: Ignasi d'Antioquia, Cartes, vol.1, Barcelona 2001.

11. En la patrística griega es característico el uso del comparativo «como» ( $\dot{\omega} \varsigma)$ en función de sacramentalidad. Ignacio ha sido el instaurador de esta terminología de la sacramentali-

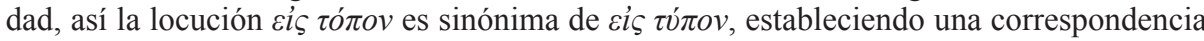
ontológica entre la eucaristía presidida por el obispo con su presbiterio y la última cena celebrada por Jesús con sus apóstoles. E. Mazza, Dall'Ultima cena all'eucaristia della Chiesa, Bologna 2014, 60-61. 
El conocido teólogo del Patriarcado ecuménico, el metropolita Juan de Pérgamo (Zizioulas), insiste en esta peculiaridad ignaciana de relacionar el presbyterium con los apóstoles. De este modo se hace presente la imagen del colegio de los apóstoles rodeando a Cristo, imagen que remite al reino de Dios, ${ }^{12}$ ya apuntado en la promesa de Jesús a los Doce (apóstoles) en Mt 19,28 y Lc $22,30 .^{13}$

Por consiguiente, se puede hablar del colegio apostólico local, si lo definimos como la comunión del obispo local (o diocesano) con su presbiterio, teniendo en cuenta que la Iglesia tiene como fundamento al mismo tiempo Cristo (1Cor 3,11) y los apóstoles (Ef 2,20; Ap 21,14), y sabiendo que es el Espíritu Santo quien garantiza este doble fundamento. Por eso aparece el trono común en los presbiterios de las antiguas iglesias catedrales (la cátedra es la sede del obispo local); y en cada ordenación presbiteral, el obispo junto con el presbiterio presente imponen las manos al ordenado de presbítero: «La unidad del presbiterio tiene una expresión litúrgica en la costumbre que determina que los presbíteros impongan las manos, después del obispo, en el rito de ordenación» (CEC 1568). ${ }^{14}$ Un gesto difícil de visibilizar en numerosas ordenaciones presbiterales latinas, pues los presbíteros van imponiendo las manos mientras van pasando, lo que hace que la gente crea que la imposición de manos que vale es la del obispo. Lo que debería visibilizarse ritualmente es que la imposición de manos del presbiterio local, junto con la plegaria de ordenación que solo recita el obispo, constituye la identidad de cada presbítero: su vínculo sacramental con todos los demás presbíteros y su obispo, pues forman un único presbiterio en cada Iglesia local, y como afirma el Vaticano II «cogobiernan» (PO 2) la Iglesia local. Y para poder llevarlo a cabo existe el consejo presbiteral $(P O 7)$, que representa el colegio apostólico en torno a Cristo en el ámbito de una Iglesia local.

12. Ibíd., 301; I. Zizioulas, L'Église et ses institutions. Textes réunis par l'Archimandrite Grigorios Papathomas et Hyacinthe Destivelle, Paris 2011, 349-367. Más ampliado en la tesis de Zizioulas publicada en Atenas el 1965, y traducida primero al francés: L'Eucharistie, l'Évêque et l'Église durant les trois premiers siècles, Paris 1994.

13. Sólo Lucas la coloca en la última cena: J. Fontbona, Bautismo-Confirmación y Eucaristia, Barcelona 2021, 136-146.

14. Statuta Ecclesiae Antiqua (siglo v), c. 91: «Cuando se ordena un presbítero y el obispo lo bendice y le pone la mano sobre la cabeza, también los demás presbíteros presentes tocan con sus manos la cabeza del ordenado» (DH 327). De ordinatione (editio typica altera 1990), 105: «Los presbíteros que asisten en la celebración de una ordenación, de pie y al mismo tiempo que el obispo, imponen las manos a los candidatos por el hecho de tener 'un espíritu común y del todo semejante con él’ (Tradición Apostólica 8)». 


\section{a) La colegialidad episcopal}

El obispo que preside la vida de la Iglesia local está sacramentalmente unido (personalmente), por la ordenación episcopal y la inserción de su sede en la comunión de las Iglesias (communio Ecclesiarum), con los demás obispos (colegialmente) y con las demás Iglesias locales (sinodalmente). Concretamente, con los obispos forma un collegium: el colegio episcopal, que tiene la misión de cuidar la comunión de las Iglesias locales.

El interesante estudio de A. Miltos muestra que la idea de la colegialidad episcopal del Concilio Vaticano II no es la misma que la de Cipriano de Cartago, pues el esquema del Vaticano II es: Pedro/Papa y Doce/obispos; en cambio el modelo de Cipriano es: Pedro + apóstoles/Papa y Pedro + apóstoles/obispos. ${ }^{15}$ Este autor nota que Cipriano nunca emplea el término collegium para hablar de los apóstoles, y además nunca habla de los Doce sino de los apóstoles. ${ }^{16}$

Es más, para Cipriano la cathedra Petri representa tanto la igualdad de los obispos como la sucesión apostólica, pues cada obispo es sucesor de Pedro y de los apóstoles; y de este modo todo el episcopado sucede a los apóstoles y a Pedro. ${ }^{17}$ Por otro lado, para Cipriano el presbyterium no representa la unidad que forma la cathedra Petri y el colegio apostólico, pues es representada por el corpus episcoporum (el colegio episcopal). ${ }^{18}$

La Iglesia primitiva siempre contempla al colegio apostólico incluyendo a Pedro, y nunca concibe el papel del obispo de Roma al margen del colegio episcopal. En efecto, Cipriano siempre incluye al obispo de Roma dentro del colegio episcopal, nunca al margen ni por encima, ${ }^{19}$ como hará por primera vez el Concilio Vaticano I. En la carta al obispo de Roma Esteban (Ep 68), Cipriano usa tres veces el término collegium ( $E p$ 68, 2,1; 3,2; 4,3) y siempre incluye al obispo de Roma, por ejemplo:

Debes, pues, escribir una carta muy explícita a nuestros hermanos obispos de la Galia para que no consientan más que el obstinado y soberbio Marción, el enemigo de la divina piedad y de la salud fraterna, insulte a nuestro colegio (collegio nostro) $\left(\right.$ Ep 68,2,1). ${ }^{20}$

15. A. Miltos, Collégialité et synodalité, 357. El análisis en las p. 359-369.

16. Ibíd., 355-356.

17. Ibíd., 356.

18. Ibíd., 360.

19. P. Zmire, «Recherches sur la collégialité épiscopale dans l'Église d'Afrique», Recherches Augustiniennes et Patristiques 7 (1971) 43.

20. St. Cebrià, Epistolari, vol. 2, Barcelona 1931, 90. 
En cambio, el Vaticano II, en la estela abierta por el Vaticano I, separa el colegio episcopal del Papa, pues el Papa puede actuar solo o con el colegio episcopal ( $L G 22),{ }^{21}$ aun sabiendo que el Papa no es un súper-obispo, sino un obispo, pero con una misión y papel crucial como obispo de la Iglesia de Roma. Así pues, la primacía del obispo de Roma se enmarca dentro del marco de la igualdad sacramental de todos los obispos. ${ }^{22}$ En pocas palabras, en la única Iglesia de Dios, Iglesia de Iglesias, existe una única autoridad suprema: el cuerpo episcopal con el obispo de Roma (nunca sin él); lo cual ha sido notado especialmente en el Concilio Vaticano II con la fórmula conclusiva una cum patribus (el obispo de Roma unido con todos los obispos). ${ }^{23}$

El problema de la comprensión católica romana de la colegialidad es el hecho de desvincular al obispo de una Iglesia local, pues lo que importa es ser miembro del colegio episcopal antes que obispo de una Iglesia local, mientras que en los orígenes era impensable un obispo sin una Iglesia local real. Ahora y para mantener esta relación con una sede a algunos obispos se les concede una antigua sede histórica: son los obispos titulares (pues poseen el título de una sede ya inexistente).

Así pues, debería matizarse mejor la existencia del colegio episcopal como realidad previa a las Iglesias locales e incluso independiente de las mismas, pues debería afirmarse la real simultaneidad e inclusión entre el episcopado único y la Iglesia única; por consiguiente, hay una relación vinculante entre el colegio episcopal y la comunión de las Iglesias. ${ }^{24}$ En este caso, los obispos auxiliares, los nuncios y los obispos de la Curia siguen siendo una anomalía en la eclesiología de comunión. Es oportuno recordar que cada Iglesia episcopal manifiesta al mismo tiempo toda la Iglesia y la sucesión de los apóstoles.

21. $L G$ 22: «El colegio o cuerpo de los obispos, por su parte, no tiene autoridad, a no ser que se considere en comunión con el Romano Pontífice, sucesor de Pedro, como cabeza del mismo, quedando totalmente a salvo el poder primacial de éste sobre todos, tanto pastores como fieles. Porque el Romano Pontífice tiene sobre la Iglesia, en virtud de su cargo, es decir, como vicario de Cristo y pastor de toda la Iglesia, plena, suprema y universal potestad, que puede siempre ejercer libremente. En cambio, el cuerpo episcopal, que sucede al colegio de los apóstoles en el magisterio y en el régimen pastoral, más aún, en el que perdura continuamente el cuerpo apostólico, junto con su cabeza, el Romano Pontífice, y nunca sin esta cabeza, es también sujeto de la suprema y plena potestad sobre la Iglesia universal (Relatio oficial de Zinelli, en el Concilio Vaticano I: Mansi, 52, 1.109C), si bien no puede ejercer dicha potestad sin el consentimiento del Romano Pontífice».

22. Juan Pablo II, Ut unum sint 94.

23. J. Fontbona, El ministeri de comunió en l'Església avui, 238.

24. J. Fontbona, «El decret Christus Dominus», en Concili Vaticà II. Constitucions, Decrets, Declaracions (edició bilingüe), Barcelona 2003, 114. 


\section{b) La colegialidad presbiteral}

Por la ordenación sacramental, los presbíteros son constituidos miembros del presbyterium o del colegio apostólico local Así pues, cada presbítero es co-presbítero. En efecto, la ordenación presbiteral crea simultáneamente presbíteros y presbiterio. ${ }^{25}$ Esto también sucede con los religiosos, los cuales antes de recibir la ordenación, deben hacer la promesa de obediencia al obispo diocesano, ${ }^{26}$ es decir, a la cabeza del presbyterium local donde queda vinculado sacramentalmente.

La innovación que supone la introducción, en la segunda edición típica del Ritual de la ordenación de obispo, presbiteros y diáconos, de la promesa de obediencia, posibilita que el religioso, con carisma propio, tome conciencia de lo que le supone recibir la ordenación al presbiterado. En efecto, el don recibido no anula el propio carisma, sino que lo sitúa en el presbiterio local donde ha sido incorporado (colegio apostólico local) y al servicio del segmento de humanidad donde se inserta la Iglesia diocesana en que reside, pero también al servicio de su misión en aquel lugar juntamente con el pueblo fiel local (rasgo sinodal). El presbítero religioso queda implicado, pues, en la pastoral de la diócesis donde reside y al servicio de la comunidad sacerdotal diocesana. Los documentos conciliares y post-conciliares acentúan la unidad del presbiterio diocesano en la acción pastoral, incluidos los religiosos. ${ }^{27}$

Cada presbítero no es una individualidad acabada, aislada; ni el presbyterium es una suma de presbíteros; el presbyterium es una comunión (una unidad en la diversidad), y ningún presbítero puede existir al margen del presbiterio diocesano; si lo hiciera, sería un anti-presbítero y no un co-presbítero (tal como lo es por la ordenación). ${ }^{28}$

El obispo diocesano es impensable sacramentalmente sin los presbíteros de su diócesis, que forman con él la realidad colegial del presbyterium (= obispo + presbíteros). El hecho de que el Concilio Vaticano II, en su decreto sobre el ministerio y la vida de los presbíteros Presbyterorum ordinis (PO), defina a los presbíteros como «necesarios colaboradores y consejeros» (necessarios adiutores et consiliarios: PO 7) del propio obispo diocesano, es

25. De ordinatione (editio typica altera), $101 ; L G 28$.

26. De ordinatione (editio typica altera), 125.

27. Christus Dominus 35; Carta Apostólica en forma de Motu proprio Ecclesiae sanctae (6/08/1966); CIC 678 y 681; Mutuae relationes, núms. 36-37. En el n. 74, la Exhortación apostólica postsinodal Pastores dabo vobis, S. Juan Pablo II recuerda que los presbíteros religiosos residentes y actuantes en una Iglesia local forman parte, a título diverso, del único presbiterio diocesano.

28. L. Trujillo, «La comunión de la Iglesia y el presbítero», Surge 54 (1996) 163-198. 
la justificación eclesiológica de la existencia del consejo del presbyterium como estructura colegial permanente de la Iglesia local.

Por consiguiente, al ser constitutivo del presbítero existir en relación y caminar con todos los demás presbíteros y su obispo, tal como afirma el Vaticano II (PO 2: «cogobiernan»), existe el consejo presbiteral o del presbyterium $(P O$ 7), en el cual los presbíteros religiosos deben tener en el mismo una representación. ${ }^{29}$

El Motu proprio Ecclesiae sanctae (6/08/1966) de Pablo VI instituye, en el seno del único presbyterium, el consejo presbiteral (n. 15), como grupo o senado de presbíteros que representan al presbiterio diocesano. La finalidad de este consejo consiste en colaborar eficazmente con su obispo en el gobierno de la diócesis. En el seno de este consejo, el obispo diocesano escucha a sus presbíteros, les consulta y discierne con ellos las necesidades de la acción pastoral y el bien pastoral de la diócesis. ${ }^{30}$ Esta idea se recoge en el Código de Derecho Canónico latino:

En cada diócesis debe constituirse el consejo presbiteral, es decir, un grupo de sacerdotes que sea como el senado del obispo, en representación del presbiterio, cuya misión consiste en ayudar al obispo en el gobierno de la diócesis según la norma del derecho, para proveer lo más posible al bien pastoral de la porción del pueblo de Dios que se le ha confiado (CIC 495 §1).

El consejo del presbyterium manifiesta la comunión sacramental y la unidad de misión de todos los presbíteros (incluidos los religiosos) con su obispo. Se trata, pues, de una institución colegial que manifiesta la comunión sacramental de todo el presbyterium (cabeza y cuerpo) y que sirve al gobierno de la diócesis (in regimine dioeceseos) ${ }^{31}$ La concelebración eucarística es la fuente de esta sacramentalidad del presbyterium presidido por su obispo. En resumen, la raíz de la unidad del presbyterium es sacramental: unión a Cristo cabeza y pastor y misión recibida in solidum. Presbíteros y obispo diocesano comparten misión y responsabilidad en el gobierno, pues todos constituyen un único presbiterio. ${ }^{32}$ El Código de Derecho Canónico latino (CIC 500,3) reconoce que el consejo presbiteral nunca puede actuar sin el obispo diocesano, pues es su cabeza.

29. Congregación para los Religiosos y los Institutos seculares y Congregación para los obispos, Mutuae relationes. Las relaciones entre los obispos y los religiosos en la Iglesia (14/05/1978), n. 56.

30. Enchiridion Vaticanum 2,782.

31. PO 7; CIC 495,1; Directorio para el ministerio pastoral de los obispos Apostolorum Successores $(22 / 2 / 2004) 182$.

32. $L G$ 28: «Unum presbyterium cum suo Episcopo constituunt». 
El consejo del presbyterium pertenece a la estructura de la Iglesia local, es indispensable. En cambio es facultativo el consejo episcopal (CIC 473 $\S 4$ ), aunque habitualmente a este último se le considere como consejo de gobierno, cuando de hecho es el equipo de vicarios que el obispo diocesano ha escogido para realizar lo que decide el auténtico consejo de gobierno. En definitiva, solo el consejo del presbyterium participa formalmente como cuerpo presbiteral en el gobierno de la Iglesia local. Su función es diferente a la del consejo pastoral diocesano, formado por presbíteros, religiosas, laicos y laicas, ${ }^{33}$ pues mientras el consejo presbiteral es un organismo colegial, el consejo pastoral es sinodal.

La relación obispo-presbíteros tiene un doble sentido: del mismo modo que el presbítero no puede prescindir de su obispo, tampoco este puede prescindir de sus necesarios consejeros y colaboradores. En algunos casos, el obispo necesita el consensus de su consejo presbiteral (y no solo consultarlo); en concreto, el canon $500 \S 2$ dice: «El consejo presbiteral tiene solo voto consultivo; el obispo diocesano debe escucharlo en los asuntos de mayor importancia, pero necesita su consentimiento solo en los casos definidos por el derecho».

Con todo, aunque el Código latino enumera los casos en los que el obispo diocesano debe consultarlo, no indica, sin embargo, los casos en los que debe pedir su consenso. Por su parte, el actual Directorio para el ministerio pastoral de los obispos (2004) insiste en que el obispo también debe consultar al consejo presbiteral en todos los demás casos de mayor importancia. ${ }^{34}$ En concreto, la ley canónica establece que debe ser consultado en les siguientes cuestiones particulares: cánones 461 (convocación del sínodo diocesano); 515 §2 (erección, supresión y modificación de parroquias); $1215 \S 2$ (erección de iglesias); $1222 \S 2$ (reducción de una iglesia a uso profano); 1263 (tributos).

La relación dinámica y creativa (colegial) entre obispo y presbíteros peligra cuando el obispo diocesano no decide con su consejo presbiteral, cuando el consejo episcopal ocupa el lugar del consejo presbiteral. Se trata de no poner en peligro la misma gracia presbiteral dada por el Espíritu a la Iglesia, o sea, la de ser buen colaborador (en la acción pastoral) y consejero (en el gobierno pastoral) del orden episcopal.

En consecuencia, el obispo local precisa de su presbiterio, como Cristo precisa de los Doce apóstoles para que estén con él, prediquen el evangelio

33. CIC 551-514; 443,5; 463,1,5; Apostolorum successores 184.

34. Apostolorum successores 182. 
del Reino y luchen contra las fuerzas del mal (Mc 3,14.15). En segundo lugar, porque un presbítero solo al frente de una comunidad no es un obispo: no ha recibido el don del episcopado, y por tanto, nada puede hacer ni deshacer sin tener en cuenta a su obispo y a los otros compañeros presbíteros. Y en tercer lugar, porque el consejo presbiteral debe ser el órgano de gobierno de cada diócesis para su bien (bene esse) y para la edificación de la Iglesia local como comunión (unidad en la diversidad), y para que el evangelio llegue a todos los rincones (ámbitos, periferias) de la diócesis. A pesar de ello, en la situación actual perdura un talante que hace innecesario que el obispo local precise del consejo y del discernimiento de su colegio apostólico local para el gobierno de su diócesis. Es muy importante que cada párroco sea consciente de que no es el obispo del lugar, y que no olvide que forma parte del único presbiterio local.

Por consiguiente, el obispo debería facilitar que los presbíteros puedan ejercer el don recibido de aconsejar y discernir en la acción de gobierno y en la salvaguarda de la comunión diocesana. Nuestros obispos también deberían preocuparse de que no se esté atrofiando el don del Espíritu recibido en la ordenación presbiteral. En efecto, los presbíteros reciben el don para colaborar con el obispo y aconsejarle en el gobierno pastoral (spiritus

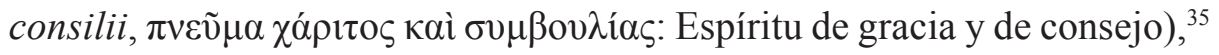
aunque la actual plegaria de ordenación (basada en el Sacramentario de Verona) acentúe la recepción del Espíritu de santidad, precisamente porque los presbíteros deben ser santos para que conduzcan al pueblo santo de Dios a la santidad. ${ }^{36}$

En resumen, los presbíteros son colaboradores necesarios y consejeros de su obispo (PO 7), lo secundan siempre en el gobierno y en la acción pastoral, o sea, en la evangelización y en la congregación de los dispersos en el único cuerpo de Cristo, el rasgo escatológico de toda acción pastoral. ${ }^{37}$ Hay que insistir en un dato primitivo: presbíteros y obispo local participan del ministerio de Cristo y de los apóstoles; el trono común es su manifestación visible en las sedes episcopales.

35. La antigua liturgia de ordenación al presbiterado (recogida, por ejemplo, en Tradición Apostólica, Constituciones Apostólicas) del Oriente y del Occidente indica esta peculiaridad.

36. De ordinatione (editio typica altera), 112. Donde se subraya la función santificadora del presbítero y se alude a la cualidad necesaria para la configuración con Cristo, el «sacrificio sin mácula». En la estela de Lumen gentium 28.

37. Sobre este punto, cf. J. Fontbona i Missé, El ministeri de comunió en l'Església avui, Barcelona 2021, 193. 


\section{LA SINODALIDAD DEL MINISTERIO APOSTÓLICO}

El rasgo sinodal caracteriza el caminar juntos el sacerdocio ministerial con el sacerdocio común en el seno de una Iglesia local determinada, o en el seno de una agrupación de Iglesias locales, o en el seno de la comunión de las Iglesias locales; ciertamente de manera organizada o estructurada, ya que cada ordenado forma parte de la comunidad de los fieles por los sacramentos de la iniciación cristiana (bautismo, confirmación y eucaristía) y no puede prescindir de la misma, pues está vinculado sacramentalmente con ella. La incardinación en una Iglesia local, con la recepción del diaconado, recuerda el rasgo sinodal del sacramento del Orden.

Ciertamente la sinodalidad es un rasgo esencial de la naturaleza relacional de la Iglesia como comunión y de la misma naturaleza del ministerio apostólico. El obispo que preside la vida de la Iglesia local está sacramentalmente unido, por la ordenación episcopal y la inserción de su sede en la comunión de las Iglesias (communio ecclesiarum), con los demás obispos y demás Iglesias locales. Con los obispos forma el único colegio episcopal, que tiene la misión de cuidar la comunión de las Iglesias locales. Por eso, cada obispo recibe en su ordenación episcopal «la plenitud del sacramento del Orden» ( $L G 26$ ) en la comunión y en la solicitud por todas las Iglesias (sollicitudo omnium Ecclesiarum: $C D$ 6; $L G 23$ ), sobre las cuales el episcopado como tal tiene el cuidado pastoral.

A través del espacio-tiempo, las Iglesias han ido estructurándose sinodalmente a nivel local, supralocal y ecuménico. Esta estructuración triádica se enraíza en el carácter colegial y representativo de la acción de los obispos ( $L G 22 ; 23)$ y en la catolicidad de la única Iglesia de Dios ( $L G 23)$.

El Concilio Vaticano II ( $L G 23$ ) afirma que los coetus episcopales (agrupaciones de obispos) ayudan a vivir la sinodalidad en un nivel intermedio entre el local y el universal. Pero estos coetus episcopales son percibidos más como reuniones de obispos que como reunión de Iglesias locales representadas por sus obispos locales o diocesanos. Más aún, el Vaticano II descubre la iniciativa de la divina providencia en la voluntad de agruparse las diferentes Iglesias locales de un mismo territorio. Debería tenerse en cuenta que si la Conferencia episcopal se considera únicamente una reunión de obispos, no puede considerarse un organismo sinodal, sino colegial. Como organismos sinodales están los concilios particulares, que agrupan las Iglesias locales de una provincia eclesiástica (se denominan entonces provinciales) o de la misma Conferencia episcopal (se denominan entonces plenarios). 
El obispo de Roma Francisco nota que, si se quiere avanzar hacia una inaplazable renovación eclesial (EG 27), ${ }^{38}$ debe activarse la sinodalidad eclesial en el seno de la comunión de todas las Iglesias locales. ${ }^{39} \mathrm{Y}$ esta activación está en continuidad con la reforma conciliar del Vaticano II. ${ }^{40}$

Todo el Pueblo santo de Dios, por la unción del Espíritu, está llamado a evangelizar y a transformar las realidades heridas por el poder del mal con la fuerza recibida del mismo Espíritu y con el ejemplo de Jesucristo. La acción común del pueblo santo de Dios es la búsqueda del reino de Dios ( $L G 31$ ).

El ministerio apostólico está al servicio de esta acción común -evangelizadora y transformadora. Y para que sea eficaz debe dotarse de estructuras que lo faciliten. Y por aquí apuntamos la reforma de la Iglesia. En concreto, debería facilitarse que el laicado se sienta responsable de la misión de la Iglesia y que se cuente con él al diseñar los planes pastorales diocesanos. ¿Cuántos planes pastorales diocesanos se realizan al margen de los movimientos apostólicos y de los consejos pastorales? Aún cuesta darse cuenta de que el Espíritu, cuando habla a la Iglesia, habla para todo el pueblo santo de Dios, no solo a sus servidores por el don recibido en la ordenación.

Hay que promover, pues, las estructuras sinodales para escuchar lo que el Espíritu dice a nuestras Iglesias locales (Ap 2-3), para que no se apague la acción del Espíritu en el seno de nuestras diócesis $(1 \mathrm{Te}$ 5,19). Ciertamente, un modo de no entristecer al Espíritu Santo (Ef 4,10; Is 63,10) y de contagiar la alegría del evangelio es ejercer el don recibido en el bautismo y en la ordenación. Y por eso, debemos recuperar la conspiratio (convergencia) entre todos los miembros del pueblo de Dios. Y si hay que recuperarlo es porque se ha perdido; en efecto, tanto los Padres de Oriente como los de Occidente valoraban la christianorum populorum condordissima fidei conspiratio y el papel que esta desempeñaba en las cuestiones importantes referentes a la fe y las costumbres. Así pues, debemos recuperar el consenso entre todo el pueblo santo de Dios. Y para ello ya existen estructuras sinodales en cada diócesis. En estas estructuras sinodales se ejerce el consenso activando el sentido de la fe (sensus fidei) de cada fiel, para que converjan en una adhesión vital (consensus fidelium) a una doctrina de fe o a un elemento de la praxis cristiana. Un sentido de la fe y un ejercicio del consenso bastante atrofiados por la poca actividad sinodal en nuestras diócesis.

38. Francisco, Exhortación apostólica Evangelii gaudium, núm.27. M. Semeraro, «In atto: a che punto è la riforma della Curia», Il Regno-attualità (2/2018) 1-7.

39. C. M. Galli, «Líneas teológicas, pastorales y espirituales del magisterio del Papa Francisco», Medellín 43 (2017) 130-134.

40. Ibíd., 128. 
El Documento sobre el sentido de la fe en la vida de la Iglesia de la Comisión Teológica Internacional (CTI) valora la importancia de consultar a los fieles, indicando que lo sean «adecuadamente para el bien de la Iglesia» (n. 120). Además recuerda que la práctica de consultar a los fieles no es una novedad en la historia de la Iglesia (n. 122), ya que, en la Edad Media, la Iglesia tenía presente el principio romano de tratar y aprobar por todos lo que afecta a todos (quod omnes tangit, ab omnibus tractari et approbari debet). Talante que se consideró una praxis y una tradición apostólicas (n. 122).

Ha llegado, pues, el momento de activar las estructuras de consulta para interactuar el sacerdocio común y el sacerdocio ministerial, respetando siempre los carismas mutuos, escuchando y considerando como propias experiencias y preocupaciones (n. 126). Y en palabras del documento sobre el sensus fidei de la CTI: "Una escucha llena de humildad a todos los niveles y una consulta adecuada de los afectados son aspectos esenciales de una Iglesia viva y viviente" (n. 126). Por consiguiente debe facilitarse en todos los ámbitos (fe, sacramentos y gobierno) este instinto de pensar con la Iglesia, compartiendo una fe común y un mismo propósito (n. 128), uniendo a todo el pueblo de Dios y revitalizando la igualdad radical (de raíz sacramental) de todas las personas bautizadas.

Finalmente, es preciso no olvidar que realizamos una importante experiencia sinodal en la eucaristía dominical. En primer lugar, porque la sinodalidad es el modo de vivir la comunión con Dios y con los pobres y entre nosotros; en otras palabras: la sinodalidad brota de la comunión, y la eucaristía es el sacramento por excelencia de la comunión. En segundo lugar, porque la misma celebración lo manifiesta, pues todos - como un solo cuerpo-celebramos unidos con Cristo, por Él y en Él en la comunión del Espíritu Santo. $\mathrm{Y}$ en tercer lugar, porque la misma plegaria eucarística lo manifiesta. Pero no se percibe y parece que no implique a toda la comunidad sacerdotal o asamblea celebrante.

La Iglesia católica romana tiene una plegaria eucarística que manifiesta y expresa muy bien la experiencia sinodal del sacerdocio común y del sacerdocio ministerial, y es precisamente la más usada en todo el mundo latino, y quizá por eso este aspecto pasa desapercibido. La plegaria eucarística segunda tiene una estructura literaria muy antigua y muy sencilla: dos acciones de gracias y una súplica. Entre las dos acciones de gracias se encuentra el Sanctus, la primera epíclesis, el relato institucional y el memorial. La primera acción de gracias se conoce como prefacio; en él agradecemos a Dios su acción en la historia de la humanidad, especialmente en la creación y la redención. En la segunda acción de gracias, en cambio, agradecemos a Dios 
lo que está realizando en este preciso momento en nuestra historia personal: nos transforma para hacernos dignos de participar en la ofrenda, que consiste en hacer su voluntad, como Jesucristo (Heb 10,9). Esta segunda acción de gracias continúa con la segunda epíclesis y termina con las intercesiones que nos adentran en la comunión de los santos.

Pero, ¿qué dice esta breve acción de gracias? «Te damos gracias porque nos haces dignos de servirte en tu presencia». Una verdadera acción de gracias que pasa bastante desapercibida y que, sin embargo, evoca una experiencia sinodal. De entrada, el sujeto de la acción de gracias es la asamblea, toda la comunidad sacerdotal. En este momento queda muy claro el ejercicio común del sacerdocio común bautismal junto con el sacerdocio ministerial: esto es la sinodalidad, caminar juntos el sacerdocio bautismal con el ministerial gracias a la acción del Espíritu. Después, conviene notar dos acciones: 1) estar de pie (adstare) ante la presencia del Señor; y 2) servirle (ministrare). ${ }^{41}$ Ciertamente es la acción gratuita de Dios Padre la que nos hace dignos de estar de pie ante Él. Esta experiencia sinodal es única pues estamos juntos ante Dios Padre sirviéndole, acompañados de su Hijo y en la comunión del Espíritu Santo. Aquí conviene recordar una imagen procedente de la cultura popular, donde se representa a la divinidad como un rey sentado y acompañado de su corte de pie ante él.

Toda la comunidad sacerdotal presente está de pie ante el trono de Dios y del Cordero (Ap 22,1), todos iguales en dignidad, por pura iniciativa de Dios, y no por nuestros méritos o ministerios y servicios. Y estamos ahí para hacer su voluntad (Heb 10,9), o sea, caminar juntos y así manifestar la comunión con Dios y con los pobres y entre nosotros.

La sinodalidad, que emana de la eucaristía y que se manifiesta y experimenta en ella, es el antídoto contra el clericalismo. En la eucaristía nos ofrecemos sirviendo el culto verdadero (Rom 12,1) y por eso podemos decir juntos (Ėंì vengo para hacer tu voluntad.

\section{CONCLUSIÓN}

En primer lugar, debería recuperarse la concepción patrística de colegialidad para aplicarla al concepto conciliar de colegio episcopal. Así pues, cada obispo es miembro del único colegio episcopal por el hecho de ser obispo de

41. E. Mazza, «Ministrare coram te: la comunità celebra il culto«, Parola, Spirito e Vita, $68(2013 / 2) 251-266$. 
una Iglesia local, lo cual garantiza el único episcopado en la única Iglesia de Dios. En consecuencia, debería revisarse a la luz del diálogo teológico con la Iglesia ortodoxa de rito bizantino la visión actual latina de la colegialidad. La dimensión colegial del episcopado supone que cada obispo está vinculado con una Iglesia local, donde existe la plenitud de la Católica mientras se mantenga en la comunión con las otras Iglesias dispersas por el mundo, y al mismo tiempo con los demás obispos de la Católica, con los cuales forma el único colegio episcopal mediante la ordenación episcopal.

En segundo lugar, los presbíteros no son individuos aislados ni medio-obispos, sino miembros del único colegio presbiteral de su Iglesia local, también mediante la ordenación presbiteral. El colegio presbiteral tiene su máxima expresión en la celebración eucarística presidida por el obispo local. La visión del trono común debería poder visibilizarse en la misión pastoral y en el gobierno diocesano. Es importante que los obispos locales valoren como órgano de gobierno al consejo presbiteral y consideren a los presbíteros como sus necesarios consejeros y colaboradores. En resumen, el presbiterio incluye siempre a su cabeza, al obispo diocesano ( $L G 28)$, pues obispo y presbíteros sacramentalmente constituyen un colegio ( $P O$ 8), el colegio apostólico local.

En tercer lugar, la dimensión sinodal del episcopado y del presbiterado debería manifestarse en las estructuras sinodales existentes a nivel diocesano e interdiocesano y a nivel parroquial e interparroquial. El Concilio Vaticano II recuerda la importancia de tener en cuenta al laicado ( $L G 37)^{42}$ y de sentirse hermano entre los hermanos y hermanas ( $P O$ 9: fratres inter fratres) por los sacramentos de la iniciación cristiana, pues la edificación del único cuerpo de Cristo ha sido confiada a todo el pueblo santo de Dios. No hay que tener miedo a consultar al pueblo santo de Dios, tal como recomiendan los últimos sínodos convocados por el obispo de Roma. No hay que olvidar que

42. «Por su parte, los sagrados pastores reconozcan y promuevan la dignidad y responsabilidad de los laicos en la Iglesia. Recurran gustosamente a su prudente consejo, encomiéndenles con confianza cargos en servicio de la Iglesia y denles libertad y oportunidad para actuar; más aún, anímenles incluso a emprender obras por propia iniciativa. Consideren atentamente ante Cristo, con paterno amor, las iniciativas, los ruegos y los deseos provenientes de los laicos (1Tes 5,19 y $1 \mathrm{Jn} 4,1)$. En cuanto a la justa libertad que a todos corresponde en la sociedad civil, los pastores la acatarán respetuosamente. Son de esperar muchísimos bienes para la Iglesia de este trato familiar entre los laicos y los pastores; así se robustece en los seglares el sentido de la propia responsabilidad, se fomenta su entusiasmo y se asocian más fácilmente las fuerzas de los laicos al trabajo de los pastores. Estos, a su vez, ayudados por la experiencia de los seglares, están en condiciones de juzgar con más precisión y objetividad tanto los asuntos espirituales como los temporales, de forma que la Iglesia entera, robustecida por todos sus miembros, cumpla con mayor eficacia su misión en favor de la vida del mundo» ( $L G 37)$. 
el pueblo santo de Dios ha recibido el Espíritu Santo en la iniciación cristiana y hay que ejercer este don y facilitarlo en las estructuras sinodales. Por eso conviene ejercitar el sentido de la fe en la vida de la Iglesia como ha recordado el citado documento de la CTI del 2014. Y desde esta sede se propone el método ecuménico de la revisión de vida para ejercitarlo. ${ }^{43}$

\section{BIBLIOGRAFÍA}

Cebrià, Sant, Epistolari, vol.2, Barcelona 1931.

Coda P. - R. Repole (eds.), La sinodalidad en la vida y en la misión de la Iglesia. Reflexiones sobre el Documento de la Comisión Teológica Internacional, Madrid 2020.

Comisión Teológica Internacional, El "sensus fidei" en la vida de la Iglesia, Madrid 2014.

Fontbona i Missé, J., "La sinodalitat", Revista Catalana de Teologia 32 (2007) 357-385.

-“Les estructures sinodals de l'Església local”, Revista Catalana de Teologia 43 (2018) 349-381.

-"Posibilidades de una reforma estructural de la Iglesia. La reforma del papado", Sal Terrae 106 (2018) 429-445.

-"El sensus fidelium y la sinodalidad de la Acción Católica”, en J.L. Martín Barrios (ed.), La sinodalidad en la vida y en la misión de la Iglesia. XLV Jornadas de Vicarios de Pastoral, Madrid 2021, 69-92.

-El ministeri de comunió en l'Església avui, Barcelona 2021.

-Bautismo-Confirmación y eucaristía, Barcelona 2021.

Galli, C. M., "Líneas teológicas, pastorales y espirituales del magisterio del Papa Francisco", Medellín 43 (2017) 95-158.

Ignasi d'Antioquia, Cartes, vol.1. Introducció, text revisat, traducció i notes de Josep Rius-Camps, Barcelona 2001.

Mazza, E., "Ministrare coram te: la comunità celebra il culto", Parola, Spirito e Vita, 68 (2013/2) 251-266.

-Dall'Ultima cena all'eucaristia della Chiesa, Bologna 2014

Miltos, A., Collégialité et synodalité. Vers une compréhension commune entre catholiques et orthodoxes, Paris 2019.

Semeraro, M., "In atto: a che punto è la riforma della Curia", Il Regno-attualità $(2 / 2018)$ 1-7.

43. J. Fontbona, «El sensus fidelium y la sinodalidad de la Acción Católica», en J. L. Martín Barrios (ed.), La sinodalidad en la vida y en la misión de la Iglesia, 77-80. 
Trujillo, L., "La comunión de la Iglesia y el presbítero", Surge 54 (1996) 163-198.

Zizioulas, I., L'Église et ses institutions, Paris 2011.

-L'Eucharistie, l'Évêque et l'Église durant les trois premiers siècles, Paris 1994.

Zmire, P., "Recherches sur la collégialité épiscopale dans l'Église d'Afrique", Recherches Augustiniennes et Patristiques 7 (1971) 3-72. 